\title{
Gender differences in chronic liver diseases in two cohorts of 2001 and 2014 in Italy
}

\author{
Evangelista Sagnelli ${ }^{1}$ (D) Tommaso Stroffolini $^{2} \cdot$ Caterina Sagnelli ${ }^{1} \cdot$ Mario Pirisi ${ }^{3} \cdot$ Sergio Babudieri ${ }^{4}$. \\ Guido Colloredo ${ }^{5}$. Maurizio Russello ${ }^{6}$. Nicola Coppola ${ }^{1}$. Giovanni Battista Gaeta $\cdot$ Bruno Cacopardo $^{8}$. \\ Massimo De Luca ${ }^{9} \cdot$ Piero Luigi Almasio ${ }^{10}$ - on behalf of EPACRON study group
}

Received: 16 June 2017 / Accepted: 10 November 2017 / Published online: 17 November 2017

○) Springer-Verlag GmbH Germany, part of Springer Nature 2017

\begin{abstract}
Background Gender differences in chronic liver disease (CLD) have been partially investigated. To extend the present knowledge, we evaluated 12,263 patients with CLD enrolled in two national surveys (9997 in 2001 and 2557 in 2014).

Methods The two surveys prospectively recruited patients aged $\geq 18$ referring to Italian liver units throughout the country using a similar clinical approach and analytical methods.

Results The overall male to female ratio (M/F) was 1.4 (7138/5124). Compared with females, males were significantly more likely to be younger (52.9 vs. 58.7 yrs.), with HBV infection alone (13.2\% vs. 9.2\%) and with alcoholic liver disease alone (11.4\% vs. 6.9\%), but less likely to show HCV infection alone (48.0\% vs. $67.9 \%)$. A male preponderance was observed in HBV-related cases (1.99) and in alcoholic-related cases (2.3), a preponderance observed both in the 2001 and in 2014 cases. In HCV-related cases, however, females predominated in 2001 (M/F 0.9) and males in 2014 (M/F 1.5). The rate of cirrhosis in alcohol-related etiology was close to $36 \%$ in both genders, a finding much higher than that observed for both sexes in HBV and HCV etiologies.Both males and females enrolled in 2014 were older $(p<0.001)$ and with a higher rate of cirrhosis and/ or HCC $(p<0.001)$ than those investigated in 2001. There was a remarkable increase over time in the proportion of male abstainers (36.7\% in 2001 and $64.3 \%$ in 2014).

Conclusion This study highlights important inter- and intra-gender differences in the characteristics and etiological factors of patients with CLD in Italy.
\end{abstract}

Keywords Chronic liver diseases · Chronic hepatitis $\cdot$ Hepatocellular carcinoma $\cdot \mathrm{HBV}$ infection $\cdot \mathrm{HCV}$ infection · Alcoholic liver diseases

\section{Abbreviations}

ALT alanine aminotransferase

CLD chronic liver disease

DAA direct acting antiviral

HBV hepatitis B virus
$\mathrm{HCV}$ hepatitis $\mathrm{C}$ virus

HCC hepatocellular carcinoma

LB liver biopsy

$\mathrm{M} / \mathrm{F} \quad$ male to female

NALFD non alcoholic fatty liver disease
Evangelista Sagnelli

evangelista.sagnelli@unicampania.it;

evangelistasagnelli@libero.it

1 Department of Mental Health and Public Medicine, University of Campania Luigi Vanvitelli, Naples, Italy

2 Department of Tropical and Infectious Diseases, Policlinico Umberto Primo, Rome, Italy

3 Department of Translational Medicine, Università del Piemonte Orientale, Novara, Italy

4 Clinic of Infectious Diseases, University of Sassari, Sassari, Italy
5 Department of Internal Medicine, San Pietro Hospital, Bergamo, Ponte San Pietro, Italy

6 Liver Unit, Hospital “G. Garibaldi” Catania, Catania, Italy

7 Infectious Diseases, Department of Mental and Physical Health and Preventive Medicine, University of Campania Luigi Vanvitelli, Naples, Italy

8 Infectious Diseases, University of Catania, Catania, Italy

9 Liver Unit, Department of Transplantation, Division of Hepatology, Cardarelli Hospital, Naples, Italy

10 Gastroenterology \& Hepatology Unit, Di.Bi.MI.S. University of Palermo, Palermo, Italy 
PBC primary biliary cholangitis

US ultrasound
2755 patients [16, 24-26]. Changes occurring over time in inter- and intra-gender differences were also evaluated.

\section{Introduction}

Because of a less frequent risk of exposure to Hepatitis $B$ virus (HBV) and an easier clearance of this infection, females harbour chronic HBV infection less frequently than males [1]. Another relevant gender difference in HBVrelated chronic liver diseases (CLD) is the more rapid progression of the disease in males than in females [2-11], partially due to the low production in males of estradiol, a potent anti-oxidant able to suppress hepatic fibrosis in animal models and to inhibit the generation of reactive oxygen species in primary culture [12].

Also hepatitis $\mathrm{C}$ virus (HCV) infection has been reported to be more frequent in men than in women, with a 2:1 male to female $(\mathrm{M} / \mathrm{F})$ ratio both in USA and Europe [13, 14], with nearly two-thirds of the subjects infected having liver abnormalities $[15,16]$. Gender plays an important role in disease progression: male sex has been identified as an independent predictor of a more severe form [17]. Liver fibrosis increases with increasing age both in males and in females, showing a linear course in men and a biphasic course in women [17]. Previous studies have identified a protective effect of estrogens on fibrogenesis due to an inhibition of stellate cell proliferation [18-20]. Accordingly, long-term studies on the natural course of $\mathrm{HCV}$ infection in anti-D immunoglobulincontaminated female cohorts showed low rates of disease progression. Only $2 \%$ in an Irish study and $0.5 \%$ in a German cohort had developed liver cirrhosis after a follow-up of 17 and 25 years, respectively [21, 22]. Thirty-five years after infection, however, $9 \%$ of the women in the German cohort had developed liver cirrhosis, suggesting that in women the disease progression may change over time in relation to the reproductive status. This has been proven in a subsequent study, showing that females pair-matched for age to males had less severe fibrosis in the reproductive/premenopausal/ early menopause stage, but a similar rate of fibrosis in late menopause compared to men [23].

It is commonly accepted that the prevalence of subjects with chronic alcohol abuse is almost double in males than in females. Chronic alcohol abuse in women is responsible for a more rapid transition to the more severe forms of liver injury because of a lower production of gastric alcohol dehydrogenase and of a smaller volume for alcohol distribution.

To obtain further information on gender differences in CLD we examined the pooled data of two Italian multicenter studies on the epidemiology and clinical presentation of CLD performed in 2001 on 9997 patients and in 2014 on

\section{Materials and methods}

\section{Patient enrolment}

The first study was performed in 2001 (Glaxo study) and was made up of 9997 patients with CLD consecutively observed at one of 79 Italian liver units for altered hepatic biochemistry or positivity of hepatitis virus markers. The second study (Epacron study) was performed in 2014 and recruited 2557 consecutive CLD patients in 16 Italian liver units. The pooled data of these 12,254 patients were analyzed to improve the knowledge on the epidemiological and clinical gender differences in CLD.

In both studies, all patients aged 18 years or more were enrolled as inpatients or outpatients. The participating units were district general or university hospitals located all over the country; several of them participated in both surveys and have cooperated for nearly 15 years in several clinical investigations using a similar clinical approach and analytical methods [24-28]. The staff of the liver units participating in the two surveys collected the data prospectively, had comparable access procedures and used a similar clinical approach and similar analytical methods.

Personal data were collected in full compliance with the Italian law on personal data protection, and each patient gave his/her informed consent to participate. All procedures applied in the two studies were in accordance with the international guidelines, with the standards of human experimentation of the local Ethics Committees and with the Helsinki Declaration of 1975, revised in 1983. At the time of the first observation, each patient signed an informed consent for the collection of personal data. Patients who agreed to undergo liver biopsy signed an appropriate informed consent before biopsy was performed. Patients were enrolled only once at their first observation. For each patient, a pre-coded questionnaire containing demographic, epidemiological and clinical data was compiled. No patient refused to participate in the studies.

\section{Diagnostic criteria}

In both surveys, the presence of HBsAg in serum identified an HBV etiology and that of anti-HCV/HCV RNA (as detected by polymerase chain reaction) identified an HCV etiology. Autoimmune chronic hepatitis, primary biliary cholangitis, hereditary hemochromatosis and Wilson's disease were diagnosed according to standardized international 
criteria [29-33]. An alcohol intake $>40 \mathrm{~g} /$ day for males ( $\geq 3$ drinks a day) and $>30 \mathrm{~g} /$ day ( $\geq 2$ drinks a day) for females for at least 5 years was considered an etiological factor for alcohol-related liver disease.

Non-alcoholic fatty liver disease was diagnosed based on abnormal serum values of alanine aminotransferase (ALT) associated with hepatic steatosis, identified by liver histology and/or ultrasound (US) in the absence of other known causes of chronic liver disease [34]. Chronic liver disease was considered cryptogenic in the absence of any viral, autoimmune or metabolic etiology.

The diagnosis of chronic hepatitis was based on liver histology, when available or on the persistence ( $>6$ months) of abnormal ALT in the absence of clinical, biochemical and US evidence of liver cirrhosis [30,35]. The diagnosis of liver cirrhosis was based on liver histology or on the characteristic clinical, biochemical, and US signs [29, 36]. The diagnosis of hepatocellular carcinoma (HCC) was based on histological and/or imaging findings and alfa-1-fetoprotein serum levels [29, 36].

Percutaneous liver biopsy (LB) was performed, if requested by the physician in care for diagnostic purposes, under US guidance using a disposable modified Menghini needle. At each liver unit, a skilled pathologist unaware of the clinical and laboratory data evaluated the liver histology. Liver necroinflammation and fibrosis were assessed by the Ishak or Metavir scoring system, and standardized criteria were used to convert the Ishak scores to the Metavir scores [37-39].

\section{Serologic assays}

Serum HBsAg and antibody to HCV were sought using commercial immunoenzymatic assays. HCV RNA was detected and quantified by a real-time PCR in a Light cycler 1.5 with a detection limit around $40 \mathrm{IU} / \mathrm{mL}$ (Roche Diagnostics, Rotkreuz, Switzerland). Routine tests were applied to seek the etiologic markers of autoimmune hepatitis, PBC, iron and copper overload and to assess liver functions.

\section{Statistical analysis}

The data were collected in a pre-established electronic CRF database (web-based data collection, e-CRF provided by Air-Tel ${ }^{\circledR}$, Airon Telematica, Milan, Italy). Differences in the means and proportions were evaluated by Student's $t$ test and the Chi-squared test, respectively. A $p$ value less than 0.05 was considered to be statistically significant. All $p$ values were two-tailed.
Table 1 Comparison of the demographic and clinical features of patients by gender (all patients)

\begin{tabular}{|c|c|c|c|c|}
\hline Variables & All patients $n=12,262$ & Male $n=7138$ & Female $n=5124$ & $p$ value \\
\hline Age (years) $($ mean $\pm S D)$ & $55.3 \pm 14.9$ & $52.9 \pm 15.1$ & $58.7 \pm 13.7$ & $<0.01$ \\
\hline $\mathrm{BMI}\left(\mathrm{kg} / \mathrm{m}^{2}\right)($ mean $\pm \mathrm{SD})$ & $25.4 \pm 3.8$ & $25.36 \pm 3.5$ & $25.1 \pm 4.2$ & $<0.01$ \\
\hline ALT (UI/l) (median, IQR) & $53,30-91$ & $56,3-97$ & $49,28-83.25$ & $<0.01$ \\
\hline \multicolumn{5}{|l|}{ Diagnosis, $N(\%)$} \\
\hline Inactive carriers & $283(2.3)$ & $1,77(2.5)$ & $106(2.1)$ & ns \\
\hline Chronic hepatitis & $8827(72.0)$ & $5125(71.8)$ & $3702(72.2)$ & ns \\
\hline Liver cirrhosis & $2667(21.7)$ & $1528(21.4)$ & $1139(22.2)$ & ns \\
\hline $\mathrm{HCC}$ & $485(4.0)$ & $308(4.3)$ & $177(3.5)$ & ns \\
\hline \multicolumn{5}{|l|}{ Country of origin, $N(\%)$} \\
\hline Italy & $11,822(96.4)$ & $6892(96.6)$ & $4930(96.3)$ & ns \\
\hline Rest of the world & $437(3.6)$ & $245(3.4)$ & $192(3.7)$ & ns \\
\hline \multicolumn{5}{|l|}{ Education, $N(\%)$} \\
\hline Primary + secondary school & $8675(74.7)$ & $4892(72.1)$ & $3783(78.2)$ & $<0.01$ \\
\hline High school/University & $2948(25.3)$ & $1897(27.9)$ & $1051(21.7)$ & $<0.01$ \\
\hline \multicolumn{5}{|c|}{ Mode of hospital admission, $N(\%)$} \\
\hline Outpatients & $9250(78.6)$ & $5363(78.5)$ & $3887(78.9)$ & ns \\
\hline Inpatients & $2511(21.4)$ & $1472(21.5)$ & $1039(21.1)$ & ns \\
\hline \multicolumn{5}{|l|}{ Alcohol intake, $N(\%)$} \\
\hline Abstainer & $6326(53.4)$ & $2886(41.7)$ & $3440(69.6)$ & $<0.01$ \\
\hline Current/past 1-2 units/day & $2994(25.2)$ & $1878(27.2)$ & $1116(22.6)$ & $<0.01$ \\
\hline Current/past $>2$ units/day & $2538(21.4)$ & $2150(31.1)$ & $388(7.8)$ & $<0.01$ \\
\hline
\end{tabular}

Some data are missing

$S D$ standard deviation; $I Q R$ interquartile range; $n s$ not significant to statistical analysis 


\section{Results}

The demographic and clinical features of the 12,263 patients by gender are shown in Table 1 . The overall male to female $(\mathrm{M} / \mathrm{F})$ ratio was $1.4(7138 / 5124)$. Males were significantly more likely to be younger ( 52.9 mean age vs. 58.7 mean age) and with more years of schooling, but less likely to be abstainers $(41.7 \%$ vs. $69.6 \% ; p<0.01)$ compared to women. No significant difference was observed by country of origin and mode of hospital admission. The stage of liver disease was similar, with a slight preponderance of HCC in males. Table 2 shows the etiological factors of liver disease. HBV etiology and alcohol-related etiology (alone or associated with HBV and/or HCV) were more frequently detected in males, whereas females showed a higher proportion of HCV-related cases. NALFD was diagnosed with a similar frequency in both sexes. Other etiologies were rare.

Table 3 shows the gender differences in the three main etiologic groups: i.e. HBV alone, $\mathrm{HCV}$ alone and alcoholrelated alone. The sex ratio (M/F) was 1.99 (939/471) in the HBV group, 0.98 (3426/3478) in the HCV group, and 2.3 $(811 / 352)$ in the alcohol-related group.

In all three groups men were significantly more likely to be younger than women. Of note, the prevalence of cases
Table 2 Etiology of liver disease by gender (all patients)

\begin{tabular}{lcccc}
\hline Variables & $\begin{array}{c}\text { All patients } \\
(n=12,262)\end{array}$ & Male $(n=7138)$ & Female $(n=5124)$ & $p$ value \\
\hline HBV alone, $N(\%)$ & $1410(11.5)$ & $939(13.2)$ & $471(9.2)$ & $<0.05$ \\
HBV plus alcohol, $N(\%)$ & $172(1.4)$ & $147(2.1)$ & $25(0.5)$ & $<0.01$ \\
HBV plus HCV, $N(\%)$ & $170(1.4)$ & $117(1.6)$ & $53(1.0)$ & $<0.05$ \\
HBV plus alcohol plus HCV, $N(\%)$ & $72(0.6)$ & $62(0.9)$ & $10(0.2)$ & $<0.05$ \\
HCV alone, $N(\%)$ & $6904(56.3)$ & $3426(48.0)$ & $3478(67.9)$ & $<0.01$ \\
HCV plus alcohol, $N(\%)$ & $1313(10.7)$ & $1042(14.6)$ & $271(5.3)$ & $<0.01$ \\
Autoimmune hepatitis/PBC, $N(\%)$ & $151(1.25)$ & $30(0.4)$ & $121(2.4)$ & $<0.01$ \\
Alcohol-related liver disease, $N(\%)$ & $1163(9.5)$ & $811(11.4)$ & $352(6.9)$ & $<0.01$ \\
NAFLD, $N(\%)$ & $561(4.6)$ & $354(5.0)$ & $207(4.0)$ & n.s \\
Wilson's disease, $N(\%)$ & $7(0.1)$ & $6(0.1)$ & $1(0.02)$ & $<0.05$ \\
Hereditary hemochromatosis, $N(\%)$ & $48(0.4)$ & $45(0.6)$ & $3(0.1)$ & $<0.01$ \\
Cryptogenic etiology, $N(\%)$ & $291(2.4)$ & $159(2.2)$ & $132(2.6)$ & n.s \\
\hline
\end{tabular}

Some data are missing

$P B C$ primary biliary cholangitis; NALFD non-alcoholic fatty liver disease; $n s$ not significant to statistical analysis

Table 3 The demographic and clinical characteristics of the three main groups with a single etiologic factor, by gender

\begin{tabular}{|c|c|c|c|c|c|c|c|c|c|}
\hline \multirow[t]{2}{*}{ Etiology } & \multicolumn{2}{|l|}{ HBV alone } & \multirow[t]{2}{*}{$p$ value } & \multicolumn{2}{|l|}{$\mathrm{HCV}$ alone } & \multirow[t]{2}{*}{$p$ value } & \multicolumn{2}{|c|}{ Alcohol abuse alone } & \multirow[t]{2}{*}{$p$ value } \\
\hline & $\begin{array}{l}\text { Male } \\
(n=939)\end{array}$ & $\begin{array}{l}\text { Female } \\
(n=471)\end{array}$ & & $\begin{array}{l}\text { Male } \\
(n=3426)\end{array}$ & $\begin{array}{l}\text { Female } \\
(n=3478)\end{array}$ & & $\begin{array}{l}\text { Male } \\
(n=811)\end{array}$ & $\begin{array}{l}\text { Female } \\
(n=352)\end{array}$ & \\
\hline $\begin{array}{l}\text { Age, } \\
\text { years } \mathrm{M} \pm \mathrm{SD}\end{array}$ & $50.6 \pm 14.1$ & $52.8 \pm 15.4$ & 0.01 & $54.0 \pm 15.4$ & $59.8 \pm 13.1$ & $<0.01$ & $54.7 \pm 13.8$ & $57.5 \pm 14.6$ & $<0.01$ \\
\hline $\begin{array}{c}\mathrm{BMI}, \mathrm{kg} / \mathrm{m}^{2} \\
\mathrm{M} \pm \mathrm{SD}\end{array}$ & $25.7 \pm 3.4$ & $24.8 \pm 4.1$ & $<0.01$ & $25.4 \pm 3.3$ & $25.0 \pm 4.0$ & $<0.01$ & $25.9 \pm 4.1$ & $25.1 \pm 4.5$ & $<0.01$ \\
\hline \multicolumn{10}{|c|}{ Diagnosis, $N(\%)$} \\
\hline $\begin{array}{l}\text { Inactive car- } \\
\text { riers }\end{array}$ & $45(4.8 \%)$ & $20(4.2)$ & ns & & & & & & \\
\hline $\begin{array}{l}\text { Chronic hepa- } \\
\text { titis }\end{array}$ & $686(73.1 \%)$ & 367 (77.9) & $<0.01$ & $2655(77.5)$ & $2622(75.4)$ & ns & $487(60.1)$ & 217 (61.6) & $<0.05$ \\
\hline Liver cirrhosis & $169(18.0 \%)$ & $70(14.9)$ & $<0.05$ & $624(18.2)$ & $738(21.2)$ & $\mathrm{ns}$ & & $126(35.8)$ & ns \\
\hline $\mathrm{HCC}$ & $39(4.2 \%)$ & $14(3.0)$ & $<0.05$ & $147(4.3)$ & $118(3.4)$ & ns & $\begin{array}{l}288(35.5) \\
36(4.4)\end{array}$ & $9(2.6)$ & $<0.05$ \\
\hline
\end{tabular}

Some data are missing

$n s$ not significant to statistical analysis 
Table 4 Comparison of the demographic and clinical features of patients in the two studies by gender

\begin{tabular}{|c|c|c|c|c|c|c|c|c|}
\hline \multirow[t]{2}{*}{ Variables } & \multicolumn{2}{|c|}{2001 Glaxo Study $(n=9752)$} & \multirow{2}{*}{$\begin{array}{l}p \text { value } \\
\mathrm{M} \text { vs. F }\end{array}$} & \multicolumn{2}{|c|}{2014 Epacron Study $(n=2510)$} & \multirow{2}{*}{$\begin{array}{l}p \text { value } \\
\mathrm{M} \text { vs. } \mathrm{F}\end{array}$} & \multirow{2}{*}{$\begin{array}{l}p \text { value } \\
\text { M } 2001 \\
\text { vs. M } \\
2014\end{array}$} & \multirow{2}{*}{$\begin{array}{l}p \text { value } \\
\text { F } 2001 \text { vs. F } 2014\end{array}$} \\
\hline & Male $(\mathrm{n}=5649)$ & $\begin{array}{l}\text { Female } \\
(\mathrm{n}=4103)\end{array}$ & & Male (n = 1489) & $\begin{array}{l}\text { Female } \\
(\mathrm{n}=1021)\end{array}$ & & & \\
\hline $\begin{array}{l}\text { Age (years) } \\
\quad(\text { mean } \pm S D)\end{array}$ & $51.7 \pm 15.2$ & $58.1 \pm 13.8$ & $<0.01$ & $57.3 \pm 14.1$ & $61.3 \pm 13.1$ & $<0.01$ & $<0.01$ & $<0.01$ \\
\hline $\begin{array}{l}\mathrm{BMI}\left(\mathrm{kg} / \mathrm{m}^{2}\right) \\
\quad(\mathrm{mean} \pm \mathrm{SD})\end{array}$ & $25.5 \pm 3.4$ & $25.0 \pm 4.1$ & $<0.01$ & $26.3 \pm 3.9$ & $25.7 \pm 4.6$ & 0.01 & $<0.01$ & $<0.01$ \\
\hline $\begin{array}{l}\text { ALT (UI/l) } \\
\text { (median, IQR) }\end{array}$ & $62(36-104)$ & $53(31-88)$ & $<0.01$ & $34(22-58)$ & $35(21-63)$ & ns & $<0.01$ & $<0.01$ \\
\hline \multicolumn{9}{|l|}{ Diagnosis, $N(\%)$ : } \\
\hline Inactive carriers & $137(2.4)$ & $86(2.1)$ & ns & $40(2.7)$ & $20(2.0)$ & ns & ns & ns \\
\hline $\begin{array}{l}\text { Chronic hepa- } \\
\text { titis }\end{array}$ & $4190(74.2)$ & $3052(74.4)$ & ns & $935(62.8)$ & $650(63.7)$ & ns & $<0.01$ & $<0.01$ \\
\hline Liver cirrhosis & $1102(19.5)$ & 849 (20.7) & ns & $426(28.6)$ & $290(28.4)$ & ns & $<0.01$ & $<0.05$ \\
\hline $\mathrm{HCC}$ & $220(3.9)$ & $116(2.8)$ & ns & $88(5.9)$ & $61(6.0)$ & ns & $<0.01$ & $<0.01$ \\
\hline \multicolumn{9}{|l|}{$\begin{array}{l}\text { Country of ori- } \\
\text { gin, } N(\%):\end{array}$} \\
\hline Italy & $5478(97.0)$ & 3969 (96.7) & ns & $1414(95.0)$ & $961(94,3)$ & ns & $<0.05$ & $<0.01$ \\
\hline $\begin{array}{l}\text { Rest of the } \\
\text { world }\end{array}$ & $171(3.0)$ & $134(3.3)$ & ns & $74(5.0)$ & $58(5.7)$ & $\mathrm{ns}$ & $<0.05$ & $<0.05$ \\
\hline \multicolumn{9}{|l|}{ Education, $N(\%)$} \\
\hline $\begin{array}{l}\text { Primary + sec- } \\
\text { ondary school }\end{array}$ & $3977(71.7)$ & $3212(79.6)$ & $p<0.01$ & 915 (73.7) & $571(71.6)$ & $<0.01$ & ns & $<0.01$ \\
\hline $\begin{array}{l}\text { High school/ } \\
\text { University }\end{array}$ & $1570(28.3)$ & $824(20.4)$ & $p<0.01$ & $327(26.3)$ & $227(28.4)$ & $<0.05$ & ns & $<0.01$ \\
\hline \multicolumn{9}{|c|}{ Mode of hospital admission, $N(\%)$} \\
\hline Outpatients & $4112(76.6)$ & $3010(76.7)$ & ns & $1251(85.3)$ & 877 (87.6) & ns & $<0.01$ & $<0.01$ \\
\hline Inpatients & $1257(23.4)$ & $915(23.3)$ & ns & $215(14.7)$ & $124(12.4)$ & ns & $<0.01$ & $<0.01$ \\
\hline \multicolumn{9}{|c|}{ Alcohol intake, $N(\%)$} \\
\hline Abstainer & $2072(36.7)$ & $2909(70.9)$ & $<0.01$ & $814(64.3)$ & $531(63.1)$ & ns & $<0.01$ & $<0.01$ \\
\hline $\begin{array}{l}\text { Current/past } \\
1-2 \text { units/day }\end{array}$ & $1475(26.1)$ & $851(20.7)$ & $<0.01$ & 403 (31.9) & $265(31.5)$ & ns & $<0.05$ & $<0.01$ \\
\hline $\begin{array}{l}\text { Current/past } \\
>2 \text { units/day }\end{array}$ & $2102(37.2)$ & $343(8.4)$ & $<0.01$ & $48(3.8)$ & $45(5.4)$ & ns & $<0.01$ & $<0.05$ \\
\hline
\end{tabular}

Some data are missing

$n s$ no significant to statistical analysis

with cirrhosis in the alcohol-related group was for both genders close to $36 \%$, a rate much higher than the corresponding figures observed in the HBV and HCV groups (Table 3).

To evaluate inter- and intra-gender differences over time, a comparison of the two studies by sex is shown in Tables 4 and 5 .

The overall sex ratio was $1.4(5649 / 4103)$ in 2001 and $1.5(1489 / 1021)$ in 2014. A much higher proportion of women were abstainers in 2001 (70.9\% vs. $36.7 \%)$, a difference no longer observed in 2014 (63.1\% vs. $64.1 \%)$ due to the increased proportion of male abstainers; other intergender differences over time are negligible. (Table 4). In both surveys a male preponderance was observed in HBV etiology (sex ratio 2.0 in 2001 and 1.9 in 2014), while in
$\mathrm{HCV}$ etiology females predominated in 2001 (M/F ratio 0.9 ) and males in 2014 (sex ratio 1.5) (Table 5). The M/F ratio both in alcohol-related liver disease and NAFLD cases showed a marked downtrend over time from $2.6(710 / 273)$ to $1.3(101 / 79)$, and from $1.96(289 / 147)$ to $1.08(65 / 60)$, respectively (Table 5 ).

The intra-gender differences over time in the two studies shows for both sexes increasing aging and an increasing proportion of subjects with a more severe chronic liver disease (i.e., liver cirrhosis and/or HCC). A marked increase in the proportion of abstainers was observed in men from $36.7 \%$ in 2001 to $64.3 \%$ in 2014 (Table 4). In both sexes the proportion of HBV-related cases increased over time, while that of HCV-related cases increased in men (from 46.7 to 
Table 5 Etiology of liver disease in the 2001 and 2014 studies by gender

\begin{tabular}{|c|c|c|c|c|c|c|c|}
\hline \multirow[t]{2}{*}{ Variables } & \multicolumn{3}{|c|}{2001 Glaxo Study $(n=9752)$} & \multicolumn{3}{|c|}{2014 Epacron Study $(n=2510)$} & \multirow{2}{*}{$\begin{array}{l}p \text { value } \\
\text { M/F } 2001 \\
\text { vs. M/F } \\
2014\end{array}$} \\
\hline & Male $(n=5649)$ & Female $(n=4103)$ & Sex ratio & Male $(n=1489)$ & Female $(n=1021)$ & Sex ratio & \\
\hline HBV alone, $N(\%)$ & $651(11.5)$ & $320(7.8)$ & 2.0 & $288(19.3)$ & $151(14.8)$ & 1.9 & ns \\
\hline HBV plus alcoho, $N(\%)$ & $129(2.3)$ & $11(0.3)$ & 11.7 & $19(1.3)$ & $14(1.4)$ & 1.4 & $<0.01$ \\
\hline HBV plus $\mathrm{HCV}, N(\%)$ & $98(1.7)$ & $40(1.0)$ & 2.5 & $19(1.3)$ & $13(1.3)$ & 1.5 & ns \\
\hline $\begin{array}{l}\mathrm{HBV} \text { plus alcohol plus } \mathrm{HCV} \text {, } \\
N(\%)\end{array}$ & $56(1.0)$ & $6(0.1)$ & 9.3 & $6(0.4)$ & $4(0.4)$ & 1.5 & 0.01 \\
\hline $\mathrm{HCV}$ alone, $N(\%)$ & $2636(46.7)$ & $2921(71.2)$ & 0.9 & $790(53.1)$ & $557(54.6)$ & 1.5 & $<0.01$ \\
\hline $\mathrm{HCV}$ plus alcohol, $N(\%)$ & $957(16.9)$ & $200(4.9)$ & 4.8 & $85(5.7)$ & $71(7.0)$ & 1.2 & $<0.01$ \\
\hline $\begin{array}{l}\text { Autoimmune hepatitis/PBC, } \\
N(\%)\end{array}$ & $10(0.2)$ & $111(2.7)$ & 0.1 & $20(1.3)$ & $10(1.0)$ & 2.0 & $<0.01$ \\
\hline $\begin{array}{l}\text { Alcohol-related liver disease, } \\
N(\%)\end{array}$ & $710(12.6)$ & $273(6.7)$ & 2.6 & $101(6.8)$ & $79(7.7)$ & 1.3 & $<0.01$ \\
\hline NAFLD, $N(\%)$ & $289(5.1)$ & $147(3.6)$ & 2.0 & $65(4.4)$ & $60(5.9)$ & 1.1 & $<0.01$ \\
\hline Wilson's Disease, $N(\%)$ & $6(0.1)$ & $1(0)$ & 6.0 & - & - & - & - \\
\hline $\begin{array}{l}\text { Hereditary hemochromatosis, } \\
\quad N(\%)\end{array}$ & $45(0.8)$ & $3(0.1)$ & 15.0 & - & - & - & - \\
\hline Cryptogenic etiology, $N(\%)$ & $62(1.1)$ & $70(1.7)$ & 0.9 & 97 (61.0) & $62(6.1)$ & 1.6 & $<0.05$ \\
\hline
\end{tabular}

Some data are missing

$n s$ no significant to statistical analysis

$53.1 \%$ ) and markedly decreased in women (from 71.2 to $54.6 \%$ ). Alcohol-related liver disease showed a downtrend from 12.6 to $6.8 \%$ in males (due to the increased proportion of abstainers), but a slight increase in women from 6.7 to $7.7 \%$. NAFLD slightly decreased in men (from 5.1 to $4.4 \%$ ), but increased in women (from 3.6 to 5.9\%). (Table 5).

\section{Discussion}

The 2001 and 2014 nationwide chronic hepatitis prevalence surveys analysed in the present study were structurally similar. Both studies were cross-sectional and prospectively enrolled inpatients or outpatients aged 18 or more with chronic liver diseases of any etiology referring for altered hepatic biochemistry or positivity for hepatitis virus markers to one of the participating liver units located throughout the country. The same clinical approach, analytical methods and facilities to access the participating liver units operating in district general or university hospitals were applied. In addition, several of these liver units had cooperated for more than a decade in several clinical investigations and participated in both the 2001 and 2014 surveys [26, 28, 40, 41]. Consequently, the pooling and comparison of data of the two studies can be considered without bias.

Males were significantly younger than females in the $\mathrm{HBV}, \mathrm{HCV}$ and alcohol-related groups, suggesting earlier exposure in life. However, also another factor may explain this phenomenon: due to the cross-sectional structure of the two studies there is the potential for a survival bias, i.e. men might have died earlier of other diseases more likely than women. The two explanations are not mutually exclusive and both could have played a role.

The comparison of the 2001 and 2014 surveys suggests that the contribution over time of females to the burden of chronic liver diseases in Italy has significantly increased in alcohol-related CLD and in NALFD. The reduced M/F ratio in the alcohol-related etiology, alone or associated with HBV and/or HCV, may be attributable to the dramatic increase in the rate of male abstainers. These data are in line with the consistent linear reduction in alcohol abuse in the last decade in Italy in both sexes [39], possibly due to the efforts of the Italian Health Authorities to prevent alcohol abuse and to the economic crisis persisting in our country for over a decade and probably reducing the likelihood of purchasing alcoholic beverages.

Of interest is the shift over time in the $\mathrm{M} / \mathrm{F}$ ratio from 0.9 to 1.5 in $\mathrm{HCV}$ cases. This different gender trend may be partially explained by the substantial change in the abortive practice in the late seventies' in Italy. Abortion in Italy before 1978 was illegal and at a high risk of exposure to parenterally transmitted viruses, especially when hemorrhagic complications required the transfusion of blood units not tested at that time for anti-HCV [42, 43]. Abortion became legal in Italy in 1978 and, as performed free of charge in hospitals, illegal procedures became less 
frequent. The illegal practice before 1978 mostly concerned women who at the time ranged in age from 18 to 45 years. This cohort of women were 41-68 years old in the 2001 survey and 54-81 years old in the 2014 survey, when, being older, they might have had a greater likelihood to have developed liver cirrhosis or HCC.

The finding that females in the HCV- and alcoholrelated groups were significantly older and with a more likely presence of liver cirrhosis than those in the HBV group (35.8 and $21.2 \%$, respectively, versus $14.9 \%$ ) might also reflect a biphasic course in disease progression in women [17] due to changes in the reproductive status $[12,23]$. (Table 3) In fact, the increase in liver fibrosis in females was reported to be more rapid in late menopause than in the reproductive/premenopausal/early menopausal status [23]. In the present study, females in late menopause and with more severe fibrosis were more likely to be included in the HCV- and alcohol-related groups than in the HBV group (Table 3).

NAFLD is an emerging cause of chronic liver disease in industrialized countries, and, consequently, of metabolic disorders, due to the steady increase in the number of subjects with a sedentary lifestyle. In line with this tendency, the present study shows an increasing proportion of patients with NAFLD from 2001 to 2014. However, it is likely that the prevalence of this etiology is largely underestimated in this and other studies because NALFD is frequently asymptomatic and most patients seek medical care only when symptoms emerge. This hypothesis is supported by the data of a study on the general population of a small town in southern Italy showing NAFLD as a putative cause of $24 \%$ of cases with altered liver biochemistry [44]. The reduction observed in the $\mathrm{M} / \mathrm{F}$ ratio of NAFLD cases may reflect changes over time in lifestyle.

Finally, the significantly older age and the higher proportion of cirrhosis and HCC cases both in males and females in the 2014 study reflects pattern of changes over time in both genders.

In conclusion, this study highlights several inter- and intra-gender differences in the characteristics and etiological factors of subjects with chronic liver diseases in Italy.

The presence of a potential referral biases affecting the figures observed should be considered: increasing attention over time to NAFLD, the availability after 2001 of new antiviral drugs against HBV that might have increased referral of HBsAg-positive patients to the prescribing liver units, and the tendency of patients with alcohol abuse to seek medical care only once symptoms of decompensation have started. These factors might have potentially affected the true prevalences and characteristics of CLD influencing the intra-gender disparity observed, but not the inter-gender differences, as both sexes have been exposed to the same possible selective factors.
The availability of effective drugs to counteract HBV infection (entecavir, tenofovir) and HCV infection DAA (direct acting antivirals), the great effectiveness of HBV universal vaccination and recent acquisitions of antiandrogenic and estrogen/estradiol capacity to delay the development of cirrhosis offers new perspectives in the study of CLDs. Published data indicate that hormone replacement therapy in post-menopausal or ovariectomized women slows the progression of fibrosis, suggesting that estradiol may play an anti-fibrotic or antiviral action [45-47], but further studies are needed to better define the nature and the extent of this action. The availability of effective nucleotide/nucleoside analogues to suppress HBV replication and the effective universal vaccination campaign against hepatitis B, at present covering all Italian subjects aged $0-35$, have reduced and will increasingly reduce the importance of HBV infection in Italy. This infection, however, remains a heavy burden for the national healthcare system of Italy, where the huge flow of migrants arriving from countries with moderate or high HBV endemicity poses major screening and vaccination problems. Finally, representing the end-stage Italian observational findings of $\mathrm{HCV}$ related CLD, the data of the present study may be used as a reference to evaluate the effectiveness of DAA therapy in Italy.

\section{Acknowledgements The EPACRON study group:}

Coordinating group: Piero Luigi Almasio, Giovanni Battista Gaeta, Evangelista Sagnelli, Tommaso Stroffolini.

Peripheral centres: Angelo Andriulli (Gastroenterology Unit, Fondazione "Casa Sollievo della Sofferenza" IRCCS Hospital, San Giovanni Rotondo, Foggia, Italy), Sergio Babudieri, Giuseppina Brancaccio (Infectious Diseases, Department of Mental and Physical Health and Preventive Medicine, University of Campania Luigi Vanvitelli, Italy), Bruno Cacopardo Guido Colloredo, Nicola Coppola, Massimo De Luca, Caterina Furlan (Department of Tropical and Infectious Diseases, Policlinico Umberto Primo, Rome, Italy), Anna Licata (Gastroenterology \& Hepatology Unit, Di.Bi.MI.S. University of Palermo, Italy), Filomena Morisco (Department of Clinical Medicine and Surgery, Gastroenterology Unit, University of Naples "Federico II", Naples, Italy), Mario Pirisi, Mariantonietta Pisaturo (Division of Infectious Diseases, AORN Sant'Anna e San Sebastiano di Caserta, Caserta, Italy), Floriano Rosina (Hepatogastroenterology Division, Ospedale Gradenigo, Turin, Italy), Maurizio Rusello, Caterina Sagnelli, Teresa Santantonio (Department of Clinical and Experimental Medicine, University of Foggia, Foggia, Italy), Antonina Smedile (Department of Gastroenterology, Molinette Hospital, Turin, Italy)

Financial support An unrestricted grant for the study was provided by Gilead.

\section{Compliance with ethical standards}

Conflict of interest All the authors of the manuscript declare that they have no conflict of interest in connection with this paper. 


\section{References}

1. Blumberg BS, Sutnick AI, London WT, Melartin L. Sex distribution of Australia antigen. Arch Intern Med. 1972;130:227-31 (PMID:4262014).

2. McMahon BJ, Alberts SR, Wainwright RB, Bulkow L, Lanier AP. Hepatitis B-related sequelae. Prospective study in 1400 hepatitis B surface antigen-positive Alaska native carriers. Arch Intern Med. 1990;150:1051-4.

3. Chen DS. Natural history of chronic hepatitis B virus infection: new light on an old story. J Gastroenterol Hepatol. 1993;8:470-5.

4. Poynard T, Ratziu V, Charlotte F, Goodman Z, McHutchison J, Albrecht J. Rates and risk factors of liver fibrosis progression in patients with chronic hepatitis C. J Hepatol. 2001;34:730-9.

5. Lee CM, Lu SN, Changchien CS, Yeh CT, Hsu TT, Tang JH, et al. Age, gender, and local geographic variations of viral etiology of hepatocellular carcinoma in a hyperendemic area for hepatitis B virus infection. Cancer. 1999;86:1143-50.

6. Evans AA, Chen G, Ross EA, Shen FM, Lin WY, London WT. Eight-year follow-up of the 90,000-person Haimen City cohort: i. Hepatocellular carcinoma mortality, risk factors, and gender differences. Cancer Epidemiol Biomark Prev. 2002;11:369-76.

7. Chang MH, Shau WY, Chen CJ, Wu TC, Kong MS, Liang DC, et al. Hepatitis B vaccination and hepatocellular carcinoma rates in boys and girls. J Am Med Ass. 2000;284:3040-2.

8. Taylor BC, Yuan JM, Shamliyan TA, Shaukat A, Kane RL, Wilt TJ, et al. Clinical outcomes in adults with chronic hepatitis B in association with patient and viral characteristics: a systematic review of evidence. Hepatology. 2009;49:S85-95. https://doi. org/10.1002/hep.22929.

9. Stroffolini T. The changing pattern of hepatitis B virus infection over the past three decades in Italy. Dig Liver Dis. 2005;37:622-7.

10. Boix R, Cano R, Gallego P, Vallejo F, Fernández-Cuenca R, Noguer I, Larrauri A. Hepatitis $C$ hospitalizations in Spain, 2004-2013: a retrospective epidemiological study. BMC Health Serv Res. 2017;17:461.

11. Sanna A, Le Strat Y, Roudot-Thoraval F, Deuffic Burban S, Carrieri P, Delarocque-Astagneau E, Larsen C. Severe liver disease related to chronic hepatitis $\mathrm{C}$ virus infection in treatment-naïve patients: epidemiological characteristics and associated factors at first expert centre visit, France, 2000 to 2007 and 2010 to 2014. Euro Surveill. 2017;22:30582.

12. Shimizu I, Kohno N, Tamaki K, et al. Female hepatology: favorable role of estrogen in chronic liver disease with hepatitis B virus infection. World J Gastroenterol. 2007;13:4295-305.

13. Armstrong GL, Wasley A, Simard EP, McQuillan GM, Kuhnert WL, Alter MJ. The prevalence of hepatitis C virus infection in the United States, 1999 through 2002. Ann Intern Med. 2006;144:705-14.

14. Rantala M, van de Laar MJ. Surveillance and epidemiology of hepatitis B and C in Europe: a review. Euro Surveill. 2008;13:18880.

15. Giusti G, Ruggiero G, Galanti B, Piccinino F, Sagnelli E, Gallo C. Chronic active hepatitis in Italy: a multicentric study on clinic and laboratory data of 1,154 cases. Hepatogastroenterology. 1983;30:126-30.

16. Sagnelli E, Stroffolini T, Mele A, Almasio P, Coppola N, Ferrigno $\mathrm{L}$, et al. The importance of $\mathrm{HCV}$ on the burden of chronic liver disease in Italy: a multicenter prevalence study of 9,997 cases. J Med Virol. 2005;75:522-7.

17. Poynard T, Bedossa P, Opolon P. Natural history of liver fibrosis progression in patients with chronic hepatitis $\mathrm{C}$. The OBSVIRC, METAVIR, CLINIVIR, and DOSVIRC groups. Lancet. 1997;349(9055):825-32.

18. Bissell DM. Sex and hepatic fibrosis. Hepatology. 1999;29:988-9.
19. Ashcroft GS, Dodsworth J, van Boxtel E, Tarnuzzer RW, Horan MA, Schultz GS, et al. Estrogen accelerates cutaneous wound healing associated with an increase in TGF-beta1 levels. Nat Med. 1997:3:1209-15.

20. Lieber CS. Medical disorders of alcoholism. N Engl J Med. 1995;333:1058-65.

21. Kenny-Walsh E. Clinical outcomes after hepatitis $\mathrm{C}$ infection from contaminated anti-D immune globulin. Irish Hepatology Research Group. N Engl J Med. 1999;340:1228-12333 (PMID:10210705).

22. Wiese M, Grüngreiff K, Güthoff W, Lafrenz M, Oesen U, Porst $\mathrm{H}$, et al. Outcome in a hepatitis $\mathrm{C}$ (genotype $1 \mathrm{~b}$ ) single source outbreak in Germany-a 25-year multicenter study. J Hepatol. 2005;43:590-8.

23. Villa E, Vukotic R, Cammà C, Petta S, Di Leo A, Gitto $S$, et al. Reproductive status is associated with the severity of fibrosis in women with hepatitis C. PLoS ONE. 2012;7:e44624. https://doi. org/10.1371/journal.pone.0044624.

24. Sagnelli E, Stroffolini T, Sagnelli C, Smedile A, Morisco F, Furlan C, et al. Epidemiological and clinical scenario of chronic liver diseases in Italy: data from a multicenter nationwide survey. Dig Liver Dis. 2016;48:1066-71. https://doi.org/10.1016/j. dld.2016.05.014.

25. Stroffolini T, Sagnelli E, Gaeta GB, Sagnelli C, Andriulli A, Brancaccio G, et al. Characteristics of liver cirrhosis in Italy: evidence for a decreasing role of HCV aetiology. Eur J Intern Med. 2017;38:68-72. https://doi.org/10.1016/j.ejim.2016.10.012.

26. Sagnelli E, Stroffolini T, Mele A, Imparato M, Almasio PL, Italian Hospitals' Collaborating Group. Chronic hepatitis B in Italy: new features of an old disease-approaching the universal prevalence of hepatitis B e antigen negative cases and the eradication of hepatitis D infection. Clin Infect Dis. 2008;46:110-3.

27. Sagnelli E, Stroffolini T, Mele A, Imparato M, Sagnelli C, Coppola N, et al. Impact of comorbidities on the severity of chronic hepatitis B at presentation. World $\mathrm{J}$ of Gastroenterol. 2012;18:1616-21.

28. Stroffolini T, Sagnelli E, Mariano A, Craxí A, Almasio P, Italian Hospitals Collaborating Group. Characteristics of HCV positive subjects referring to hospitals in Italy: a multicentre prevalence study on 6,999 cases. J Viral Hepat. 2006;13:351-4.

29. ht t p://www.eas l. eu/research/our-contributions/clinical-practice-guidelines/detail/ recommendations-on-treatment-of-hepatitis-c-2015.

30. Taal BG, Schalm SW, ten Kate FW, Hermans J, Geertzen RG, Feltkamp BE. Clinical diagnosis of primary biliary cirrhosis: a classification based on major and minor criteria. Hepatogastroenterology. 1983;30:178-82.

31. Alvarez F, Berg PA, Bianchi FB, Burroughs AK, Cancado EL, Chapman RW, et al. International autoimmune hepatitis group report: review of criteria for diagnosis of autoimmune hepatitis. J of Hepatol. 1999;31:929-38.

32. Adams PC, Chakrabarti S. Genotypic/phenotypic correlations in genetic hemochromatosis: evolution of diagnostic criteria. Gastroenterology. 1998;114:319-23.

33. Ferenci P, Caca K, Loudianos G, Mieli-Vergani G, Tanner S, Sternlieb I, et al. Diagnosis and phenotypic classification of Wilson disease. Liver Int. 2003;23:139-42.

34. Angulo P, Lindor KD. Non-alcoholic fatty liver disease. J Gastroenterol Hepatol. 2002;17:S186-90.

35. Bruix J, Sherman M, Llovet JM, Beaugrand M, Lencioni R, Burroughs AK, et al. Clinical management of hepatocellular carcinoma. Conclusions of the Barcelona-2000 EASL conference. European Association for the Study of the Liver. J Hepatol. 2001;35:421-30.

36. Gaiani S, Gramantieri L, Venturoli N, Piscaglia F, Siringo S, D'Errico A, et al. What is the criterion for differentiating chronic hepatitis from compensated cirrhosis? A prospective study 
comparing ultrasonography and percutaneous liver biopsy. J Hepatol. 1997;27:979-85.

37. Ishak K, Baptista A, Bianchi L, Callea F, De Groote J, Gudat $\mathrm{F}$, et al. Histological grading and staging of chronic hepatitis. $\mathrm{J}$ Hepatol. 1995;22:696-9.

38. Bedossa P, Poynard T. An algorithm for the grading of activity in chronic hepatitis C. The METAVIR Cooperative Study Group. Hepatology. 1996;24:289-93.

39. Gamal S, Khaled Z. Ishak versus METAVIR: terminology, convertibility and correlation with laboratory changes in chronic hepatitis C, liver biopsy. In: Takahashi H, editor. InTech 2011. Chap 10. https://doi.org/10.5772/20110.

40. Sagnelli E, Stroffolini T, Mele A, Imparato M, Sagnelli C, Coppola $\mathrm{N}$, et al. Impact of comorbidities on the severity of chronic hepatitis B at presentation. World J Gastroenterol. 2012;18:1616-21.

41. Scafato E, Gandin C, Galluzzo L, Martire S, Ghirini S. Epidemiologia emonitoraggio alcol-correlato in Italia e nelle Regioni.Valutazione dell'Osservatorio Nazionale Alcol-CNESPS sull'impatto del consumo di alcol ai fini dell'implementazione delle attività del Piano Nazionale Alcol e Salute. RAPPORTI ISTISAN 14/1. 2014.https://www.ars.toscana.it/files/aree_intervento/alcol/Rapporto_ISTISAN_1_2014_alcol_regioni.pdf. Accessed 14 Nov 2017
42. Brusaferro S, Barbone F, Andrian P, Brianti G, Ciccone L, Furlan A, et al. A study on the role of the family and other risk factors in HCV transmission. Eur J Epidemiol. 1999;15:125-32.

43. Gheorghe L, Csiki IE, Iacob S, Gheorghe C, Smira G, Regep L. The prevalence and risk factors of hepatitis $\mathrm{C}$ virus infection in adult population in Romania: a nationwide survey 2006-2008. Gastrointest Liver Dis. 2010;19:373-9.

44. Pendino GM, Mariano A, Surace P, Caserta CA, Fiorillo MT, Amante A, et al. Prevalence and etiology of altered liver tests: a population-based survey in a Mediterranean town. Hepatology. 2005;41:1151-9.

45. Ulitzky L, Lafer MM, KuKuruga MA, Silberstein E, Cehan N, Taylor DR. A new signaling pathway for HCV inhibition by estrogen: gPR30 activation leads to cleavage of occludin by MMP-9. PLoS ONE. 2016;11:e0145212.

46. Di Martino V, Lebray P, Myers RP, Pannier E, Paradis V, Charlotte F, et al. Progression of liver fibrosis in women infected with hepatitis C: long-term benefits of estrogen exposure. Hepatology. 2004;40:1426-33.

47. Zheng B, Zhu YJ, Wang HY, Chen L. Gender disparity in hepatocellular carcinoma (HCC): multiple underlying mechanisms. Sci China Life Sci. 2017;60:75-584. 